\title{
Comparison of Success Rate of Arterio-venous Fistula in Patients with Diabetes Vs Non-diabetes
}

Karki K, Banepali N, Hirachand S, Mukhiya R, Shrestha RKN

Department of Surgery, KIST Medical College Teaching Hospital, Imadol, Lalitpur

Correspondence: Dr Kushal Karki, Lecturer, Department of Surgery, KIST Medical College Teaching Hospital email kushal295@yahoo.com

\begin{abstract}
Introduction and objective: Definition of chronic renal disease is based on the presence of kidney damage or glomerular filtration rate (GFR $60 \mathrm{ml} / \mathrm{min}$ per $1.73 \mathrm{~m}^{2}$ ) for 3 months, irrespective of cause[1]. Once they are diagnosed as CKD, they are kept either on hemodialysis or peritoneal dialysis or patient undergo renal transplant. [2,3] With this research we may prove that even in a similar circumstances failure rate of AVF is more in diabetes patient.
\end{abstract}

Materials and Methods: Total 50 patients of either gender were taken in this study.Inclusion criteria: CRF with $\mathrm{GFR}<30 \mathrm{ml} / \mathrm{min}$. Arterial diameter $>1.5 \mathrm{~mm}$ and venous diameter $>2 \mathrm{~mm}$. Preoperative radial artery blood flow $>30 \mathrm{~cm} / \mathrm{min}$. Exclusion criteria: arterial diameter $<1.5 \mathrm{~mm}$ venous diameter $<2 \mathrm{~mm}$.Written consent was taken from the patient. After preoperative workup surgery was done by $1^{\text {st }}$ author.Arterio-venous fistula wasscanned by color Doppler imaging after 4 weeks.

Result: There were 31[62\%] male, 19[38\%] female. Mean age of patients was 55.8 years. 18 [36\%] were dialysis dependent. Cause of renal failure were diabetes 16(32\%), unknown 15(30\%), glomerulonephritis 8[16\%] and obstructive uropathy $3[6 \%]$. Mean internal diameter of radial artery was $1.91 \mathrm{~mm}$ [1.5-2.6] and cephalic vein 2.57mm [1.9-3.2].7 patients had swelling of arm, 5 patients has surgical site infections and 15 patients had primary failure; 11 were from diabetic group and 4 from non-diabetic group. Mean duration of surgery was 60.95 minutes [50-75]. Average preoperative velocity in radial artery was 32.94 [30-39] cm/sec. Average flow of blood at the end of 4 weeks was $461.42 \mathrm{ml} / \mathrm{min}$ [0-654]. Between two groups failure rate was significantly high in diabetic patients[p $=0.02]$. Failure rate was significantly higher in patients with diabetes more than 10 years $[p=0.01]$.

Conclusion: Failure rate of arterio-venous fistula is significantly high in diabetic patients.

Key words: CRF, arterio-venous fistula, diabetes mellitus 